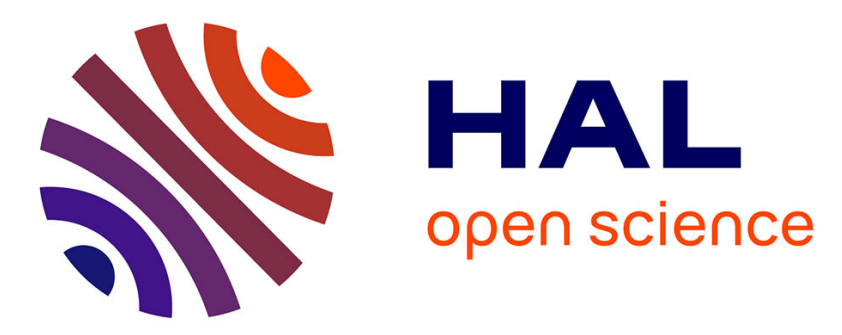

\title{
Dietary antioxidants prevent age-related retinal pigment epithelium actin damage and blindness in mice lacking $\alpha \mathbf{v} \beta 5$ integrin
}

\author{
Chia-Chia Yu, Emeline Nandrot, Ying Dun, Silvia C Finnemann
}

\section{- To cite this version:}

Chia-Chia Yu, Emeline Nandrot, Ying Dun, Silvia C Finnemann. Dietary antioxidants prevent agerelated retinal pigment epithelium actin damage and blindness in mice lacking $\alpha \mathrm{v} \beta 5$ integrin. Free Radical Biology and Medicine, 2011, 52, pp.660 - 670. 10.1016/j.freeradbiomed.2011.11.021 . hal03086755

\section{HAL Id: hal-03086755 \\ https://hal.science/hal-03086755}

Submitted on 17 Nov 2021

HAL is a multi-disciplinary open access archive for the deposit and dissemination of scientific research documents, whether they are published or not. The documents may come from teaching and research institutions in France or abroad, or from public or private research centers.
L'archive ouverte pluridisciplinaire HAL, est destinée au dépôt et à la diffusion de documents scientifiques de niveau recherche, publiés ou non, émanant des établissements d'enseignement et de recherche français ou étrangers, des laboratoires publics ou privés. 


\title{
Dietary antioxidants prevent age-related retinal pigment epithelium actin damage and blindness in mice lacking $\alpha \mathrm{v} \beta 5$ integrin
}

\author{
Chia-Chia Yu ${ }^{a}$, Emeline F. Nandrot ${ }^{\text {b,c,d }}{ }^{\text {, Ying Dun }}{ }^{\text {a }}$, Silvia C. Finnemann ${ }^{\text {a,* }}$ \\ a Department of Biological Sciences, Fordham University, Bronx, NY 10458, USA \\ b Institut National de la Santé et de la Recherche Médicale, U968, Paris 75012, France \\ c Institut de la Vision, Université Pierre et Marie Curie-Paris 06, UMR_S 968, Paris 75012, France \\ d Centre National de la Recherche Scientifique, UMR_7210, Paris 75012, France
}

\section{A R T I C L E I N F O}

\section{Article history:}

Received 12 August 2011

Revised 8 November 2011

Accepted 14 November 2011

Available online 8 December 2011

\section{Keywords}

Actin

Age-related blindness

Antioxidant

Cytoskeleton

4-Hydroxynonenal

Lipofuscin

Oxidative stress

Protein oxidation

Retina

Retinal pigment epithelium

Free radicals

\begin{abstract}
A B S T R A C T
In the aging human eye, oxidative damage and accumulation of pro-oxidant lysosomal lipofuscin cause functional decline of the retinal pigment epithelium (RPE), which contributes to age-related macular degeneration. In mice with an RPE-specific phagocytosis defect due to lack of $\alpha \mathrm{v} \beta 5$ integrin receptors, RPE accumulation of lipofuscin suggests that the age-related blindness we previously described in this model may also result from oxidative stress. Cellular and molecular targets of oxidative stress in the eye remain poorly understood. Here we identify actin among 4-hydroxynonenal (HNE) adducts formed specifically in $\beta 5^{-/-}$RPE but not in neural retina with age. HNE modification directly correlated with loss of resistance of actin to detergent extraction, suggesting cytoskeletal damage in aging RPE. Dietary enrichment with natural antioxidants, grapes or marigold extract containing macular pigments lutein/zeaxanthin, was sufficient to prevent HNE-adduct formation, actin solubility, lipofuscin accumulation, and age-related cone and rod photoreceptor dysfunction in $35^{-/-}$mice. Acute generation of HNE adducts directly destabilized actin but not tubulin cytoskeletal elements of RPE cells. These findings identify destabilization of the actin cytoskeleton as a consequence of a physiological, sublethal oxidative burden of RPE cells in vivo that is associated with agerelated blindness and that can be prevented by consuming an antioxidant-rich diet.
\end{abstract}

(c) 2011 Elsevier Inc. All rights reserved.
Photoreceptor rod and cone neurons do not renew themselves in the adult human eye. Their long-term viability and function depend on lifelong support by neighboring retinal pigment epithelial (RPE) cells. Because of this critical and continuous dependence of photoreceptors on RPE cells, any functional deficiency of RPE cells ultimately harms photoreceptors and impairs vision.

Like photoreceptors, RPE cells are postmitotic in the mature human eye and do not turn over. Therefore, they are themselves susceptible to cumulative damage acquired over time. The most profound visible change characteristic of human RPE cells with age is the enormous accumulation of lipofuscin, a complex mixture of partially digested, oxidized protein and lipid photoreceptor derivatives formed and trapped in RPE lysosomes [1-3]. In a harmful positive-feedback loop, oxidative stress promotes lipofuscin formation and existing lipofuscin further exacerbates oxidative stress [4,5]. Lipofuscin also acts as photosensitizer

Abbreviations: AMD, age-related macular degeneration; CSB, cytoskeleton stabilization buffer; ERG, electroretinography; HNE, 4-hydroxynonenal; PFA, paraformaldehyde; POS, shed photoreceptor outer segment tips; RPE, retinal pigment epithelium; TLC, thin-layer chromatography; wt, wild type.

* Corresponding author. Fax: + 17188173514.

E-mail address: finnemann@fordham.edu (S.C. Finnemann). and may contribute to inflammation [6]. Both inflammatory processes and oxidative damage contribute to dysfunction, distress, and death of RPE cells that cause atrophic age-related macular degeneration (AMD), the most common form of AMD that affects millions of the elderly worldwide $[7,8]$. It is generally assumed that increasing, sublethal levels of endogenous oxidative stress directly contribute to development of AMD. However, it is unknown which cell type (RPE or photoreceptor cells) and which molecules or mechanisms are particularly vulnerable and damaged by increased oxidative burden in the aging eye.

A major support function of RPE cells is the diurnal phagocytosis and digestion of photoreceptor outer segment tips (POS) shed by photoreceptors in a circadian rhythm. Healthy RPE cells respond to POS shedding with a burst of phagocytosis and complete digestion of shed debris within hours. We previously showed that $\beta 5$ integrin knockout mice ( $\beta 5^{-/-}$mice) lack the diurnal burst of RPE phagocytosis [9]. Like human patients with atrophic AMD, $\beta 5^{-/-}$mice lose visual function with age as a consequence of primary deficiencies of RPE cells, which accumulate pro-oxidant lipofuscin [9]. Here, we quantify and specify the effects of oxidative damage to aging retina and RPE and determine their relevance to photoreceptor function. Our results show that protein oxidation destabilizes specifically the actin cytoskeleton of aging $35^{-1-}$ 
RPE cells. Furthermore, reducing oxidative burden by consuming a natural-antioxidant-enriched diet is sufficient to prevent actin damage, lipofuscin buildup, and blindness.

\section{Materials and methods}

Reagents were from Invitrogen (Carlsbad, CA, USA) or Sigma-Aldrich (St. Louis, MO, USA) unless otherwise indicated.

\section{Animals, feeding regimen, and tissue collection}

All procedures involving animals were performed according to the National Institutes of Health Guide for the Care and Use of Laboratory Animals and reviewed and approved by the Fordham University Institutional Animal Care and Use Committee. Animals were housed under cyclic $12 \mathrm{~h}$ light: $12 \mathrm{~h}$ dark light conditions and fed ad libitum. Long Evans wild-type (wt) rats were bred to generate litters for RPE isolation. $\beta 5^{-/-}$mice were characterized in detail previously [9-11] and $\beta 5^{+/+}$wt mice of the same genetic background (129 T2/SvEmsJ) were bred to generate age-matched groups for aging studies. For dietary supplementation, littermates of $35^{-1-}$ or wt mice were raised on standard Picolab Rodent Diet 205053 (No. 5053; Purina Mills, Gray Summit, MO, USA), separated into feeding groups at 3 months of age, and fed specific diets until being sacrificed for experiments. Feeding groups received one of the following: No. 5053 chow (control diet); No. 5053 supplemented with $0.68 \%$ glucose and $0.68 \%$ fructose (sugar diet); No. 5053 supplemented with freeze-dried grape powder containing a natural mix of resveratrol, flavans, flavonols, anthocyanins, and simple phenolics supplied by the California Table Grape Commission (grape diet); and No. 5053 supplemented with 1\% FloraGlo (Kemin Health, Des Moines, IA, USA), a patented marigold extract containing $5 \%$ lutein and $0.2 \%$ zeaxanthin xanthophylls (lutein diet). All diets were custom-mixed at room temperature followed by compression and heating for less than $1 \mathrm{~s}$ to $40{ }^{\circ} \mathrm{C}$ and pelleting by the TestDiet division of Purina Mills. These procedures had previously been shown to maintain the efficacy of the compounds. Food intake and body weight of mice on the various diets were monitored weekly and remained similar over the feeding periods. Our mice on the control or lutein diet consumed $3.3 \mathrm{~g}$ of food daily and weighed $32 \mathrm{~g}$, on average. Hence, the lutein diet provided $1.65 \mathrm{mg}$ lutein and $66 \mu \mathrm{g}$ zeaxanthin per mouse per day or $52 \mathrm{mg}$ lutein/2 mg zeaxanthin per kilogram body weight. Similar lutein/zeaxanthin supplementation had shown earlier to be well tolerated by mice [12]. Supplementation with $170 \mathrm{mg}$ lutein $/ \mathrm{kg}$ bw was recently shown to prevent acute light-induced retinal oxidative damage in mice [13]. For comparison, one serving of cooked kale provides $17 \mathrm{mg}$ of lutein/zeaxanthin and commercially available supplements for human consumption commonly provide up to $30 \mathrm{mg}$ lutein and $5 \mathrm{mg}$ zeaxanthin per day. Our mice on the sugar or grape diet consumed $2.9 \mathrm{~g}$ of food daily and weighed $35 \mathrm{~g}$, on average. Hence, the grape diet provided $43 \mathrm{mg}$ freeze-dried grapes daily, which is equivalent to $236 \mathrm{mg}$ fresh grapes per mouse or $6.7 \mathrm{~g}$ fresh grapes per kilogram body weight per day. For human consumption, one serving of table grapes is set as $126 \mathrm{~g}$. Our mice on the grape diet consumed $~ 3.5$ servings of grapes per day.

For tissue harvest, mice were sacrificed by $\mathrm{CO}_{2}$ asphyxiation, a method approved by the Panel of Euthanasia of the American Veterinary Medical Association, $\sim 2 \mathrm{~h}$ after light onset. For tissue preservation for sectioning, eyeballs were immediately immersed in Davidson's fixative (32\% ethanol, $11.5 \%$ acetic acid, $8 \%$ formaldehyde). Lens and cornea were removed from fixed eyes before dehydration and paraffinembedding of the eyecups. For tissue lysis, lens and cornea were removed immediately after from each enucleated eyeball in chilled Hepes-buffered Hanks' saline solution containing calcium and magnesium to generate whole eyecups containing retina and RPE. To separate neural retinas from RPE/choroid and remaining eyecup, we incubated eyecups in Hepes-buffered Hanks' saline solution without calcium and magnesium for $5 \mathrm{~min}$ to loosen the retinal adhesion [11]. We then transferred the eyecups to an empty plastic dish and performed a single radial cut toward the optic nerve; flattened the eyecup, retina facing up; and peeled off the neural retina with forceps. Eyecups, neural retinas, and remaining eyecups containing RPE and choroid were used immediately for ELISAs or immunofluorescence assays or were flash-frozen and stored at $-80{ }^{\circ} \mathrm{C}$ for up to 2 weeks for immunoblotting or lipid extraction assays.

\section{Electroretinography}

Electroretinograms (ERGs) were recorded from age-matched groups of four or five male mice each as described previously [9]. Briefly, the mice were dark-adapted overnight before anesthesia by intraperitoneal injection of $100 \mathrm{mg} / \mathrm{kg}$ ketamine and $10 \mathrm{mg} / \mathrm{kg}$ xylazine. Topical anesthesia was induced with proparacaine hydrochloride. Pupils were dilated with phenylephrine hydrochloride and tropicamide. ERGs testing rod and cone functions in combination were recorded using a UTAS 2000 ERG recording system (LKC, Gaithersburg, MD, USA) with white flash stimuli of $1.5 \mathrm{~cd}-\mathrm{s} / \mathrm{m}^{2}$ attenuated to yield intensities from -1.8 to $0.2 \log \mathrm{cd}-\mathrm{s} / \mathrm{m}^{2}$. Stimuli were presented in order of increasing intensity. For each flash intensity, three or four recordings were averaged. ERGs testing rod and cone functions separately were recorded using an LKC UTAS system. Rod responses were recorded by exposing dark-adapted mice to $-1.6 \log \mathrm{cd}-\mathrm{s} / \mathrm{m}^{2}$ white flashes. To specifically test cone activity, mice were subjected to a steady rod-desensitizing stimulus of $20 \mathrm{~cd} / \mathrm{m}^{2}$ for $5 \mathrm{~min}$ followed by white flash stimulation at $0.4 \log \mathrm{cd}-\mathrm{s} / \mathrm{m}^{2}$. Six rod and six cone responses were averaged for each animal. For all recordings, a-wave amplitudes were measured from the baseline to the trough of the a-wave, and b-wave amplitudes were measured from the trough of the a-wave to the peak of the b-wave.

\section{RPE isolation, primary RPE cell culture, and HNE treatment}

Patches of RPE were manually isolated from eyes of adult $35^{-/-}$ mice or of 9- to 11-day-old Long Evans rat pups following a previously described procedure [14]. Purified mouse RPE was processed for HNE ELISA immediately after isolation. Purified rat RPE cells were seeded in Dulbecco's modified Eagle's medium (DMEM) supplemented with $10 \%$ fetal bovine serum in 96-well plates with or without glass coverslips and incubated at $37{ }^{\circ} \mathrm{C}$ and $5 \% \mathrm{CO}_{2}$ for 5 to 7 days. The antioxidants resveratrol, lutein, and trolox were used at 30,50 , and $20 \mu \mathrm{M}$, respectively, as these concentrations had previously been established to be effective but nontoxic for RPE cells in culture [15-17]. They were supplied in complete medium at days 3 and 5 or on day 6 before use of cells on day 7. To generate HNE adducts, cells were incubated with a fresh solution of HNE (EMD, Gibbstown, NJ, USA) in DMEM for $1 \mathrm{~h}$ before processing for lysis or fixation.

\section{Quantification of protein oxidation}

Freshly isolated individual eyes without lens, two pooled isolated neural retinae, two eyecups without neural retina, purified RPE from four eyes, or primary RPE from three wells of a 96-well plate were homogenized in $250 \mu \mathrm{l}$ phosphate-buffered saline on ice using a Tissue Tearor (Research Products International, Mount Prospect, IL, USA) for $15 \mathrm{~s}$. Cleared homogenates obtained by centrifugation at $2000 \mathrm{~g}$ for $3 \mathrm{~min}$ were used in series of twofold dilutions as samples for HNE-adduct or protein carbonyl ELISA kits (both Cell Biolabs, San Diego, CA, USA) according to the manufacturer's suggestions and using a Spectramax M2e plate reader (Molecular Devices, Sunnyvale, CA, USA). Protein concentration was quantified using Bradford reagent (Thermo Fisher, Waltham, MA, USA). 
Immunofluorescence staining and fluorescence microscopy

After removal of the neural retina, eyecups were either fixed immediately with fresh $4 \%$ paraformaldehyde (PFA) in phosphate-buffered saline or preextracted for $1 \mathrm{~min}$ with cytoskeleton stabilization buffer (CSB; $50 \mathrm{mM}$ Mes, $5 \mathrm{mM} \mathrm{MgCl}$, 3 mM EGTA, 0.5\% Triton X-100, pH 6.4) at room temperature followed by PFA fixation.

All images were acquired on a Leica TSP5 laser scanning confocal microscopy system (Leica, Wetzlar, Germany). To visualize autofluorescent lipofuscin, PFA-fixed samples were immediately mounted in Vectashield containing 4',6-diamidino-2-phenylindole (DAPI) nuclear dye (Vectorlabs, Burlingame, CA, USA). Lipofuscin image acquisition was performed by using 488-nm excitation and recording emission from 580 to $670 \mathrm{~nm}$. These imaging parameters are optimized to detect the lipofuscin chromophore A2E. They do not detect emission by all fluorophores known to be present in human lipofuscin. Three-micrometer stacks of $x-y$ sections $0.24 \mu \mathrm{m}$ apart were acquired to generate maximal projections representing the nuclear region of the RPE. DAPI nuclear counterstain was imaged subsequently. Numbers of vesicles per area were quantified by counting vesicles in lipofuscin projections as described above after conversion to gray scale. For each eyecup whole mount, vesicles in three noncontiguous $50 \times 50-\mu \mathrm{m}$ areas were counted and averaged. Five-micrometer-thick central cross sections of paraffin-embedded eyecups were stained with hematoxylin and eosin, antibodies to rhodopsin (B6-30 [18]), or R/G cone opsin (Millipore, Billerica, MA, USA) or were stained using the DeadEnd fluorimetric TUNEL kit (Promega, Madison, WI, USA) according to the manufacturer's protocol. For fluorescence microscopy of sections, nuclei were counterstained with DAPI. Images of sections show single $x-y$ confocal scans. To visualize F-actin, eyecups or rat primary RPE cells were preextracted with CSB for 1 min, fixed with PFA, and incubated with phalloidin-AlexaFluor488 before mounting with Vectashield. Stacks of $x-y$ sections $0.2 \mu \mathrm{m}$ apart were acquired to generate maximal projections representing the entire F-actin content of the RPE.

To label HNE adducts in RPE cells in culture, cells were fixed with PFA, permeabilized with $0.2 \%$ Triton X-100, and incubated with primary antibody to HNE (EMD) and secondary antibody conjugated to AlexaFluor594. To label tubulin and ZO-1, primary RPE cells were fixed with ice-cold methanol followed by incubation with mouse anti-tubulin (Abcam, Cambridge, MA, USA) and rabbit anti-ZO-1 followed by AlexaFluor488-anti-mouse antibody and AlexaFluor568anti-rabbit antibody.

\section{Autofluorescent lipid and A2E quantification}

Extraction of lipids from individual mouse eyes after removal of lens and cornea followed the method of Bligh and Dyer [19]. Dried lipid extracts were dissolved in $\mathrm{CHCl}_{3} / \mathrm{MeOH}(2 / 1)$ and spotted onto thin-layer chromatography (TLC) plates. Relative total autofluorescent lipid content was quantified by fluorescence excitation at $488 \mathrm{~nm}$ and quantification of fluorescence emission from 520 to $610 \mathrm{~nm}$ with a Typhoon Trio Imager and ImageQuant TL 7.0 (both GE Healthcare). A2E content was quantified after chromatography in $\mathrm{CHCl}_{3} / \mathrm{MeOH} / \mathrm{TFA}(93 / 6 / 1)$ of samples and varying amounts of purified A2E as standards and fluorescence scanning as described previously [20].

\section{Sample lysis, fractionation, immunoprecipitation, and immunoblotting}

To generate total protein extracts, samples were solubilized by vortexing in HNTG lysis buffer ( $50 \mathrm{mM}$ Hepes, pH 7.4, $150 \mathrm{mM} \mathrm{NaCl}$, $1.5 \mathrm{mM} \mathrm{MgCl}$, $10 \%$ glycerol, $1 \%$ Triton X-100 freshly supplemented with $1 \%$ protease inhibitor cocktail). To extract proteins not associated with the cytoskeleton (fractions "ex"), samples were incubated with CSB for $1 \mathrm{~min}$. Subsequent incubation of the remaining cell material with HNTG yielded insoluble proteins anchored in the cell by the cytoskeleton (fractions "ins"). Immunoprecipitations were performed by adding HNE antibody to precleared total protein lysates for $2 \mathrm{~h}$ with agitation followed by agitation for another $2 \mathrm{~h}$ in the presence of protein $\mathrm{G}$-agarose beads. After four washes with lysis buffer, samples were eluted by boiling in reducing SDS sample buffer. Lysates, sample fractions, or immunoprecipitates were separated by SDS-PAGE, blotted onto nitrocellulose membrane, incubated with primary antibodies and secondary antibodies conjugated to horseradish peroxidase, and developed by enhanced chemiluminescence detection (PerkinElmer, Waltham, MA, USA) using autoradiography films. Films were scanned and bands quantified using ImageJ. Primary antibodies used for detection were actin (Cell Signaling, Cambridge, MA, USA), $\alpha / \beta$-tubulin (Abcam), $\alpha$ v integrin (BD Biosciences), $\beta 5$ integrin (Santa Cruz Technology), CD81 (Biolegend), CD36 and MerTK (both R\&D Systems, Minneapolis, MN, USA), HNE (Millipore), and RPE65 (Genetex).

\section{Statistical analysis}

Student's $t$ test was used to compare control and test groups. $P$ values smaller than 0.05 were considered statistically significant.

\section{Results}

Protein oxidation increases with age in RPE/choroid but not neural retina of $\beta 5^{-1-}$ mice

Excess lipofuscin accumulation in the RPE suggested elevated oxidative stress in 1-year-old $\beta 5^{-/-}$mice [9]. To directly test whether aging $\beta 5^{-1-}$ retina accumulated oxidative damage, we measured levels of HNE-protein adducts in eyes from $\beta 5^{-1-}$ mice at 6 months of age, before lipofuscin buildup, and at 13 months of age, when lipofuscin is excessive. Fig. 1A shows that whole eyes (eyes after removal of lens but containing all other eye tissues) obtained from $\mathrm{B5}^{-/-}$mice at 6 months of age contained on average the same levels of HNE adducts as whole eyes obtained from age-matched wt mice. There was little increase in wt eyes by 13 months of age. In contrast, HNE adducts in $\mathrm{B5}^{-1-}$ eyes increased 6.7-fold from 6 to 13 months of age and significantly above levels of age-matched wt eyes. This increase was specifically due to higher levels of HNE adducts present in eyecup tissue containing the RPE and the underlying choroid after removal of the retina (Fig. $1 \mathrm{~B}, \mathrm{RPE} / \mathrm{Ch}$ ), as HNE adducts in $35^{-/-}$neural retina alone hardly differed from wt neural retina even at 13 months of age (Fig. 1B, NR). HNE-adduct levels in brain and liver tissues did not differ between 13-month-old $35^{-/-}$mice and age-matched wt mice further confirming that abnormal protein oxidation occurred specifically in RPE/choroid tissues of $\beta 5^{-1-}$ mice of age (data not shown).

\section{Dietary antioxidants prevent protein oxidation in $\beta 5^{-1-}$ RPE}

We next sought to alleviate the oxidative burden of $35^{-/-}$mice through an increase in their dietary antioxidant intake by enriching the regular diet either with grapes or with standardized marigold extract rich in lutein/zeaxanthin (for details on diets please see Materials and methods). Grapes are rich sources of numerous natural polyphenols and resveratrol and have already shown antioxidant benefits in physiological settings $[21,22]$. We supplemented the standard diet of a cohort of $35^{-/-}$mice with freeze-dried grapes (grape diet). Based on intake per body weight, mice on the grape diet consumed about 3.5 servings of grapes per day. Control groups of age-matched mice received chow matching the sugar content of grape diet (sugar diet). Lutein/zeaxanthin are macular pigments that may serve as endogenous antioxidants in the human retina and whose decline may weaken retinal antioxidant defense with age. We supplemented the standard diet of a cohort of $35^{-/-}$mice with lutein/zeaxanthin (lutein diet). Groups received the various diets for 9 months, from 4 to 13 months of age. All feeding groups tolerated the enriched chows well, consumed the 

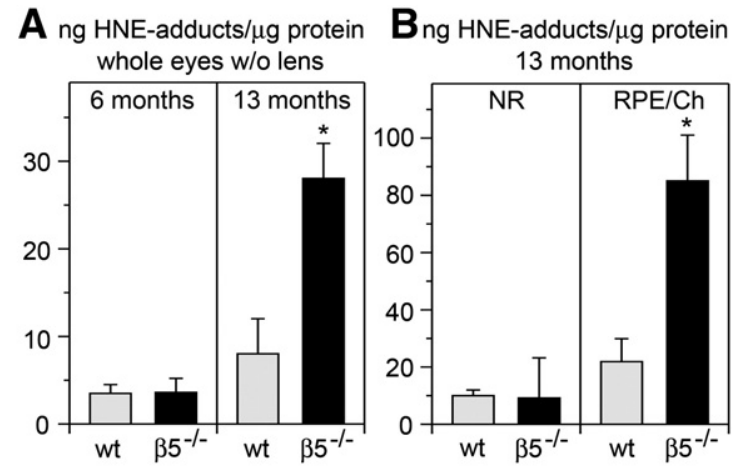

C $\%$ HNE-adducts enriched diets 4 to 13 months

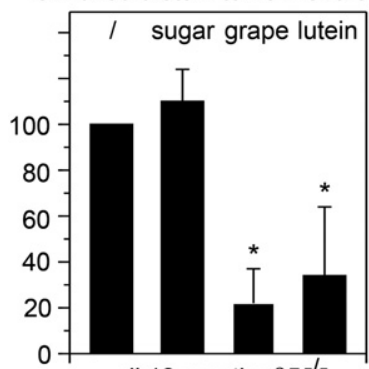

all 13 months $\beta 5^{-/}$

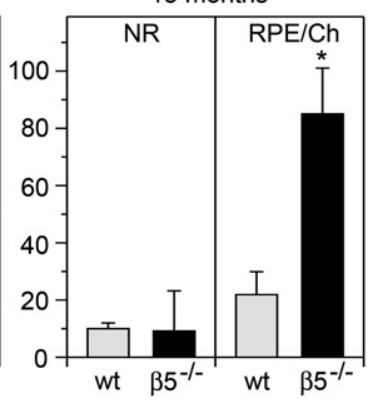

D \% protein carbonylation enriched diets 4 to 13 months

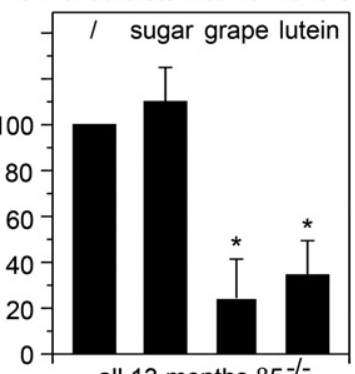

all 13 months $\beta 5^{-/-}$

Fig. 1. Antioxidant-enriched diets decrease levels of oxidized proteins accumulating specifically with age in the RPE/choroid of $35^{-1-}$ mice. Gray bars show results from wt mice, black bars show results from $35^{-/-}$mice. All bars show means $\pm \mathrm{SD}, n=4$ independent experiments each testing three eye samples derived from three different mice. Asterisks indicate significant difference comparing $B 5^{-/-}$to wt (A and $\mathrm{B}$ ) or comparing a diet group to standard chow group ( $C$ and D). (A) Absolute levels of HNE-protein adducts in wt and $B 5^{-1-}$ whole eyes without lens at 6 and 13 months of age. (B) Absolute levels of HNE adducts in neural retina (NR) and remaining eyecup without neural retina enriched in RPE and choroid (RPE/Ch) of 13-month-old wt and $B 5^{-1-}$ mice. (C and D) Relative levels of HNE adducts (C) and of protein carbonylation (D) in RPE/choroid of 13 -month-old $\beta 5^{-/-}$mice fed standard chow (/, set as $\left.100 \%\right)$ compared to sugar, grape, or lutein diet as indicated.

same amount of food, and had similar body weights on the various diets (Supplementary Fig. S1). At 13 months of age, HNE-adduct levels were similar in RPE/choroid tissues of mice on sugar diet compared to standard chow (Fig. 1C). In contrast, either grape or lutein diet dramatically decreased HNE-adduct content in RPE/choroid by 75 and 68\% compared to the appropriate respective controls. The effects of the diets were not specific to HNE-adduct formation as protein carbonylation levels decreased to the same extent (Fig. 1D).

Dietary antioxidants prevent lipofuscin buildup and age-related cone and rod photoreceptor dysfunction in $\beta 5^{-1-}$ mice

We next used fluorescence microscopy examination of RPE to test if increasing dietary antioxidants affected the buildup of autofluorescent lipofuscin-like granules we had found previously in aged $35^{-1-}$ RPE. We set our acquisition parameters to detect long-wavelengthemitting fluorophores such as the known lipofuscin component A2E because we previously found such fluorophores in $35^{-1-}$ RPE tissue sections [9]. It is important to note that human, and probably mouse, lipofuscin contains additional fluorophores that this imaging methodology does not detect. Flat-mount preparations of the RPE of mice sacrificed at 13 months of age revealed more autofluorescent granules in $\beta 5^{-/-}$RPE compared to wt RPE if the mice were fed the sugar diet (Fig. 2, compare 2B to 2A). We observed fewer autofluorescent granules in $35^{-1-}$ RPE of mice on the grape diet or on the lutein diet than in $35^{-1-}$ RPE of mice on the sugar diet (Fig. 2, compare $C$ and $\mathrm{D}$ to $\mathrm{B}$ ). This difference was not due to a restoration of the daily rhythm of POS phagocytosis in $35^{-/-}$mice fed with antioxidant
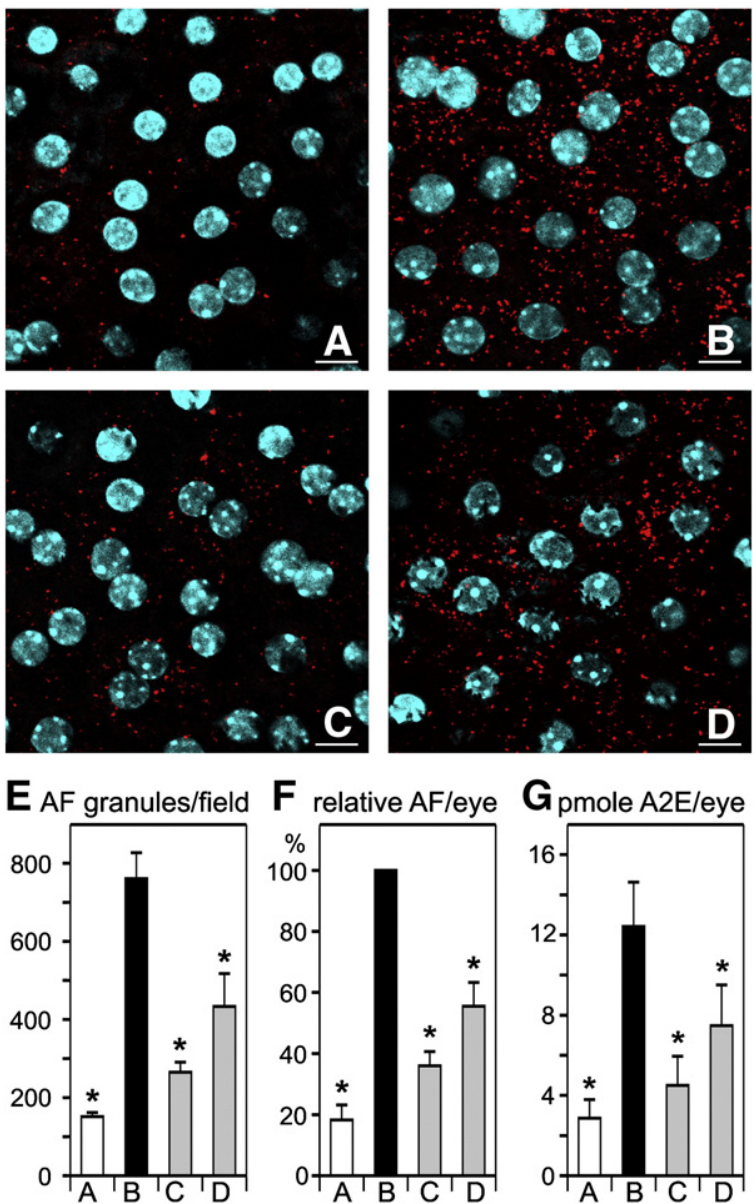

Fig. 2. Antioxidant-enriched diets limit accumulation of autofluorescent lipofuscin-like granules in the RPE of 13-month-old $35^{-/-}$mice. Images show representative en face autofluorescence signals (red) of RPE flat mounts shown with nuclear counterstain (cyan) prepared in three independent experiments each comparing three eyes of three different mice of each diet group. Fields shown are from samples processed in the same experiment. Scale bars, $20 \mu \mathrm{m}$. (A) Wt RPE of mouse fed sugar diet. (B, C, and D) $35^{-1}$ RPE of mice fed sugar diet (B), grape diet (C), or lutein diet (D). (E to G) Bar designations A to $D$ refer to the same groups of mice as in fields (A) to (D). Asterisks indicate significant difference from values obtained from $\mathrm{B5}^{-/-}$eyes on sugar diet (bars B). All bars represent means $\pm S D, n=3$ eyes from three different mice. (E) Numbers of autofluorescent granules visible per RPE flat-mount field of $50 \times 50 \mu \mathrm{m}$ in images acquired as in (A) to (D). (F) Levels of autofluorescent lipid extracted from eyes as indicated relative to levels in eyes from $35^{-1-}$ mice on sugar diet (bar B), which was set as $100 \%$. (G) Absolute levels of A2E as quantified by TLC analysis of lipid extracts from individual mouse eyes.

diets, as phagosome numbers did not increase at the time of the phagocytic peak $1 \mathrm{~h}$ after light onset (Supplementary Fig. S2). To support our microscopic observations, we employed three different methods to quantify lipofuscin load in the different aged mice. First, counting the number of autofluorescent granules per field of $50 \mu \mathrm{m}^{2}$ RPE demonstrated that aged $\beta 5^{-/-}$RPE harbors on average five times more granules than wt RPE (Fig. 2E). Grape and lutein diets reduced granule load significantly, by 65 and 43\%, respectively, but kept it significantly above the granule load of wt RPE (Fig. 2E). Second, quantifying total relative content of autofluorescent lipids extractable from eyes of the four groups of mice showed similar relative differences between mouse groups (Fig. 2F). Third, quantifying the best studied lipofuscin component, the pyridinium bis-retinoid known as A2E [4], showed significantly elevated A2E in $\mathrm{B5}^{-/-}$eyes on the control diet compared to wt eyes (Fig. 2G). Grape diet reduced A2E to levels found in wt mice (Fig. 2G). Lutein diet reduced A2E by $32 \%$ such that eyes of $\mathrm{B5}^{-/-}$mice on the lutein diet contained significantly less A2E than eyes from $\beta 5^{-/-}$mice on the sugar diet but significantly more than wt mice on the sugar diet (Fig. 2G). Altogether, 
these analyses support the conclusion that the grape diet and to a lesser extent the lutein diet reduce age-related accumulation of autofluorescent lipofuscin-like granules by $35^{-/-}$RPE.

Next, we monitored retinal light sensitivity of mice on the various diets by recording ERGs from dark-adapted mice. The much larger light response of 13 -month-old $35^{-/-}$mice fed the grape diet or the lutein diet from 4 to 13 months of age compared to the sugar diet or standard chow was immediately obvious (Fig. 3A). Quantifying ERG a-waves that indicate light responses specifically by photoreceptors from cohorts of mice on the various diets over the entire course of the feeding experiments demonstrated that either grape or lutein diet was sufficient to prevent the dramatic decline in photoreceptor function observed on both control and sugar diets with age (Figs. 3B and C). At 13 months of age, a-wave amplitudes recorded from $\mathrm{B5}^{-/-}$mice on the lutein diet were on average $31 \%$ lower than wt a-waves, compared to a $74 \%$ reduction in $35^{-/-}$mice without protective diet (Fig. 3C). b-wave amplitudes, which reflect activities of retinal interneurons, were also higher if $35^{-1-}$ mice had been fed the grape or lutein diet, by 16 and $26 \%$ on average, respectively, but differences were less pronounced than for a-waves. To more precisely unravel the effects of the various diets on responses by various retinal cell types we conducted a second feeding experiment. We repeated the original regimen, providing either sugar diet or grape diet to $\mathrm{B5}^{-1-}$ mice for 9 months starting at 3 months of age. Additionally, we raised age-matched $\beta 5^{-/-}$mice that received the grape diet for periods of 3 months only, starting at 3, 6, or 9 months of age. Given that age-related macular degeneration affects mainly cone photoreceptor function, we specifically tested cone photoreceptor function in animals of all five feeding groups at 12 months of age by performing photopic ERGs. Comparison of responses of mice fed the sugar
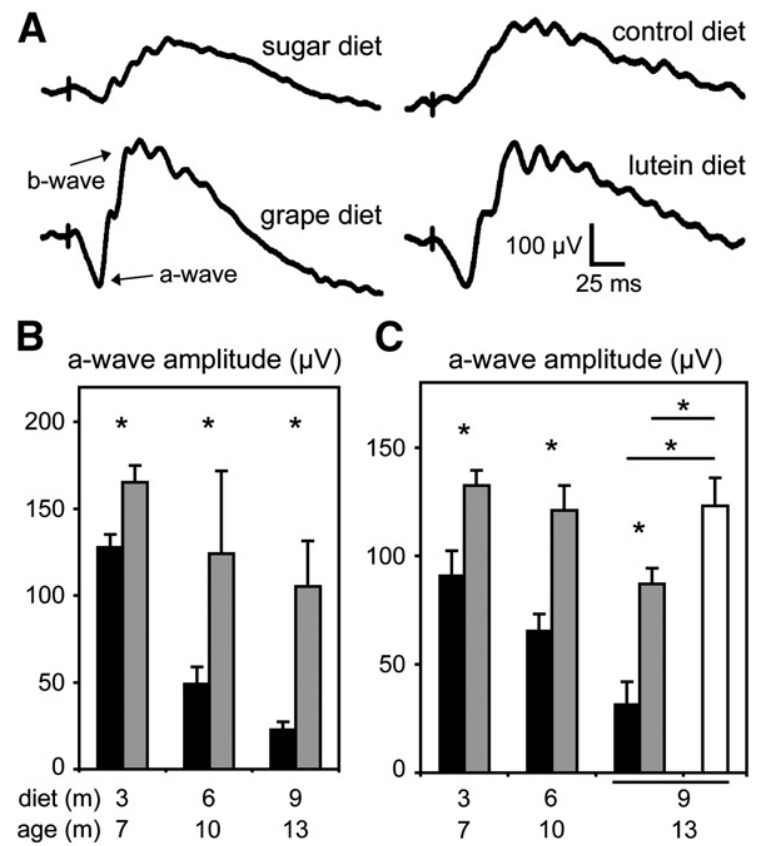

Fig. 3. Grape and lutein dietary supplementation preserves photoreceptor function in aged $35^{-/-}$mice. (A) Representative scotopic ERG recordings of response to white light flash with an intensity of $-0.22 \mathrm{log} \mathrm{cd}-\mathrm{s} / \mathrm{m}^{2}$ of 13 -month-old $\beta 5^{-/-}$mice fed the sugar or the grape diet and the control or the lutein diet for 9 months as indicated. Scale bars, latency $25 \mathrm{~ms}$, amplitude $100 \mu \mathrm{V}$. (B and C) Bars show a-wave amplitudes of ERGs recorded, like those in (A), from 7-, 10-, and 13-month-old $35^{-/-}$mice fed for 3, 6 , and 9 months with (B) sugar (black bars) or grape (gray bars) diet and (C) control (black bars) or lutein diet (gray bars). In (C), the a-wave amplitudes are compared to that of 13-month-old wt mice (white bars) fed for 9 months with control diet, as indicated. Duration of diet and age are in months $(\mathrm{m})$. Bars show means \pm SD. For each test diet, two independent groups of three to five mice each were tested against independent groups of three to five mice on control diet. Asterisks indicate significant differences between test and control diet. diet and the grape diet for 9 months revealed dramatically better cone function in mice fed the grape diet (Fig. 4A). Strikingly, cone function was improved in comparison to mice fed a lifelong sugar diet even if the mice received the grape diet only from 3 to 6 months or from 6 to 9 months of age (Fig. 4B). In contrast, grape diet consumption only from 9 to 12 months of age had no effect (Fig. 4B). The effects of the grape diet on photopic ERG b-waves were similar to those on a-waves except that for all feeding groups the differences compared to the b-waves of mice on the control diet were less pronounced (Fig. 4C). As a result, the effect on the photopic b-wave of feeding the grape diet from 3 to 6 months of age was too small to be statistically significant. To determine whether the improvements in our original feeding experiment (Fig. 3) were solely due to effects of diet on cones, we repeated ERG recordings on the same cohorts of mice 1 week after cone recordings. To detect rod photoreceptor function with minimal contributions of cones, we recorded responses of dark-adapted mice to low-intensity light flashes that are below the detection sensitivity of cones. This experiment revealed that rod function was improved-albeit to a lesser extent than cone function-in mice that received grape diet for 9 months or from 3 to 6 months or 6 to 9 months of age (Fig. 4D). Like cones, rods did not benefit if the mice consumed grape diet only late in life, from 9 to 12 months of
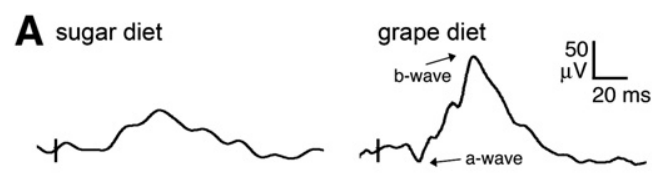

B

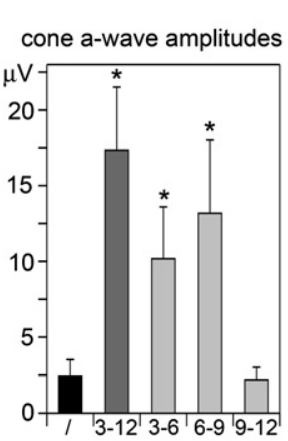

C cone b-wave amplitudes

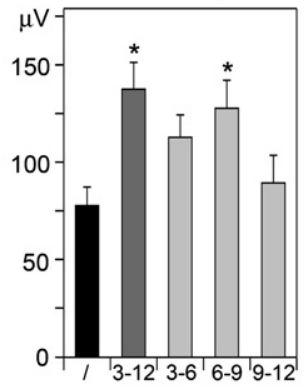

D

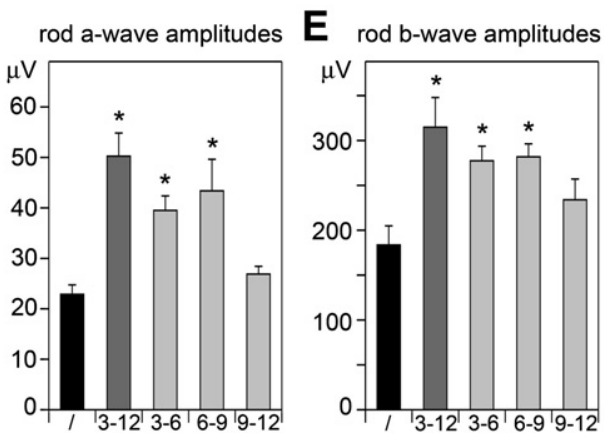

Fig. 4. Grape dietary supplementation improves cone and rod photoreceptor function even if consumed only during early or midadulthood. 12-month-old $35^{-1-}$ mice were analyzed after being fed either the sugar or the grape diet from 3 to 12 months of age or the sugar diet from 3 months of age except for a 3-month period during which they received the grape diet, from 3 to 6 months, 6 to 9 months, or 9 to 12 months of age, as indicated. (A) Representative ERG recordings of response to activation of photoreceptor cones by unattenuated white light flash of light-adapted mice fed with either the sugar or the grape diet from 3 to 12 months of age as indicated. Scale bars, latency $20 \mathrm{~ms}$, amplitude $50 \mu \mathrm{V}$. (B to E) Bar graphs show ERG response quantifications as mean wave amplitudes $\pm \mathrm{SD}, n=4$ mice per diet group, as indicated. Asterisks indicate significant differences between grape diet group compared to sugar diet group. (B) Photopic a-wave amplitudes from cone-specific recordings as in (A). (C) Photopic b-wave amplitudes from cone-specific recordings as in (A). (D and E) Scotopic a-wave (D) and b-wave (E) amplitudes of responses of dark-adapted mice to dim flashes attenuated with $2 \log$ ND representing solely rod responses. 
age (Fig. 4D). All three diet groups with improved rod a-waves also showed significantly improved rod b-waves (Fig. 4E). However, as for cones, changes in b-wave amplitudes were considerably smaller than changes in a-wave amplitudes. Although we cannot exclude a direct effect of grape diet on retinal interneuron function, we suspect that the changes in b-waves we detected are mainly a consequence of altered photoreceptor function.

We wondered if increased functionality of photoreceptors in $35^{-1-}$ mice fed an antioxidant-enriched diet was a result of prevention of photoreceptor outer segment loss or cell death. To address this question, we carefully compared retinal tissue morphology between wt and $35^{-/-}$ mice on the sugar diet and $\beta 5^{-/-}$mice on the grape diet. We did not observe obvious morphological changes between samples taken from the three groups of mice at either 6 or 12 months of age (Fig. 5A and data not shown). Rhodopsin and cone R/G opsin immunofluorescence signals did not differ among groups either (Figs. 5B and C). Morphometry detected no significant difference in photoreceptor outer or inner segment length among the groups (data not shown). Finally, TUNEL labeling did not detect apoptotic nuclei in $35^{-/-}$mouse retina at either age (Fig. 5D). Taken together, reducing the oxidative burden on RPE/ choroid by increasing dietary antioxidant intake in early and/or midlife adulthood was sufficient to significantly delay age-related blindness by improving cone and rod photoreceptor functionality independent of detectable changes in outer segment structure or photoreceptor survival.

Dietary antioxidants prevent actin-HNE adduct formation and actin destabilization in aging $\beta 5^{-/-}$RPE in situ

We next sought to specify the oxidative damage that occurred specifically in the RPE in aging $35^{-/-}$eyes and that was prevented by antioxidant supplementation. We chose to continue our experiments only on mice fed the grape diet, as it was equally as effective in preserving vision in our model as the lutein diet and represented a healthy diet of several servings of fruit a day. Quantitative immunoblotting using HNE antibodies confirmed that increased levels of HNE-protein adducts in eyes of aging $\mathrm{B5}^{-/-}$mice fed the sugar diet were significantly reduced in mice fed the grape diet (Fig. 6A). HNEmodified proteins were of various molecular sizes and were strongly enriched in the RPE/choroid eyecups compared to the neural retina (Fig. 6B). Because preventing oxidative damage to $35^{-1-}$ RPE proteins resulted in improved functionality of photoreceptor cells of the neural retina, which we found harboring little oxidative damage themselves, we reasoned that proteins relevant for photoreceptor support might be particularly damaged with age in $35^{-/-}$RPE. HNE adduct formation was not associated with altered total protein levels of any of the proteins we chose to test because of their importance for RPE structure (actin, tubulin), phagocytic function ( $\alpha \mathrm{v}$ and $\beta 5$ integrins, MerTK, CD81, and CD36), or the visual cycle (RPE65) (Fig. 6C). To determine if these candidate proteins were modified by HNE, we performed HNE immunoprecipitations from whole-eye lysates of 1-yearold mice followed by candidate protein immunoblotting. We did not detect any of our candidate proteins in HNE immunoprecipitates of wt eyes (Fig. 6D). Actin was the only one of our candidate proteins detectable in HNE immunoprecipitates of $35^{-1-}$ eyes and its abundance in the HNE eluate was dramatically decreased, by approximately ninefold, in samples obtained from mice on the grape diet (Fig. 6D). Notably, we did not detect HNE modification of $\alpha$-tubulin, which, like actin, is an abundant cytoskeletal protein of the RPE and which is shown to be particularly susceptible to HNE adduct formation in cultured fibroblasts [23]. To test if the actin cytoskeleton was also functionally altered in aging $35^{-/-}$RPE in situ, we next examined whole-mount preparations of mouse RPE labeled with the F-actin binding reagent phalloidin by fluorescence microscopy. In comparison with age-matched wt RPE, 1 -year-old $35^{-/-}$RPE showed overall reduced $\mathrm{F}$-actin levels and obvious variations in F-actin labeling intensities among RPE cells in the same tissue (Fig. 7, compare B with
A). In contrast, $\beta 5^{-/-}$RPE from mice fed the grape diet showed increased and largely even labeling of F-actin although less so than wt RPE (Fig. 7C). We did not observe obvious differences in F-actin labeling between in situ RPE from wt and $35^{-1-}$ mice at 6 months of age (data not shown). To quantify differences in F-actin content, we subjected freshly isolated mouse RPE/choroid and neural retina tissue samples to differential detergent extraction. Extracts obtained from a 1-min incubation of fresh tissues with CSB, which leaves cytoskeletal proteins intact, contained sevenfold more actin from $\mathrm{B5}^{-/-}$eyes compared to wt eyes when mice were fed the control diet (Fig. 7D, compare actin bands in ex fractions of RPE/choroid, quantification in Fig. 7E). This increase in actin solubility was almost completely prevented by feeding $35^{-1-}$ mice the grape diet. This destabilization was specific to actin in the RPE as tubulin solubility did not change with genotype and there was no change in actin or tubulin solubility in neural retina (Figs. 7D and E).

\section{The actin cytoskeleton in RPE cells is highly sensitive to direct destabilization} by HNE

Finally, we set out to determine if HNE modification was sufficient to destabilize actin in polarized RPE cells. To this end, we incubated primary RPE cells with synthetic HNE for $1 \mathrm{~h}$ before analyzing their cytoskeletal systems. HNE immunofluorescence microscopy demonstrated HNE-adduct formation (Figs. 8A and B). Immunoblotting revealed HNE-adduct formation on RPE proteins including a protein(s) of the molecular size of actin that was extractable in CSB (Fig. 8I). Phalloidin labeling after preextraction and fixation of cells showed a dramatic decrease in F-actin content upon HNE treatment (Fig. 8, compare D with C). Quantification of HNE's effect on actin stability using differential extraction revealed that this short-term treatment with HNE caused a 5.4-fold increase in soluble actin (Figs. 8I and J). Importantly, our treatment with $20 \mu \mathrm{M}$ HNE for $1 \mathrm{~h}$ had no effect on appearance or stability of the microtubule cytoskeleton (Figs. 8E, F, and I) or on the tight-junction localization of ZO-1 (Figs. 8G and $\mathrm{H}$ ). We found that disruption of microtubules and cell junctions required 1-h incubation with at least 5-fold more concentrated HNE instead (Supplementary Fig. S3). These results indicate that availability of the oxidative stress product HNE is sufficient to directly destabilize the actin cytoskeleton in RPE cells. Moreover, the actin cytoskeleton is more sensitive to HNE than the microtubule cytoskeleton in RPE cells. We wondered if our HNE incubation yielded an overall HNEadduct load similar to that of the load building up in $35^{-/-}$RPE in vivo with age. We tested this directly by measuring HNE adducts relative to total RPE protein in RPE purified from 12-month-old $35^{-/-}$mice and in primary RPE in culture harvested immediately after treatment for $1 \mathrm{~h}$ with HNE at concentrations between 1 and $20 \mu \mathrm{M}$. HNE ELISA showed that incubation with 20 and $10 \mu \mathrm{M}$ HNE generated 50 and $26 \%$, respectively, more HNE adducts than present in aged $\beta 5^{-1-}$ mouse RPE in situ (Supplementary Fig. S4A). Treatment with $5 \mu \mathrm{M}$ HNE yielded an HNE-adduct load that was on average $72 \%$ of the load of RPE in situ, which was not a statistically significant difference. Treatment with $1 \mu \mathrm{M}$ HNE generated negligible HNE-adduct load. Notably, 10 or $5 \mu \mathrm{M}$ HNE (but not 2 or $1 \mu \mathrm{M}$ HNE) destabilized F-actin significantly and to the same extent as $20 \mu \mathrm{M}$ HNE (Supplementary Fig. S4B). Thus, generation of HNE adducts at the level present in the aging $35^{-/-}$RPE is sufficient to destabilize F-actin.

Finally, we tested if antioxidants may benefit F-actin stability directly by preventing HNE-actin formation or by promoting clearance of destabilized actin. We chose to determine the efficacy of three different antioxidant compounds with different biochemical properties, purified resveratrol and lutein, in analogy to our enriched diets, and trolox, a water-soluble vitamin $\mathrm{E}$ analogue we had previously found both nontoxic and effective in reducing oxidative stress exerted by A2E on polarized RPE cultures [17]. Preincubation of primary RPE in culture with any of the antioxidants overnight or for 4 days did not 


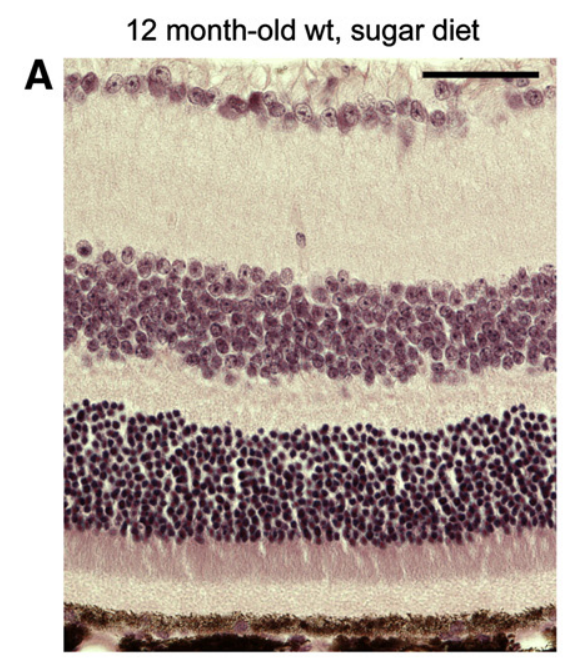

12 month-old $\beta 5^{-/}$, sugar diet

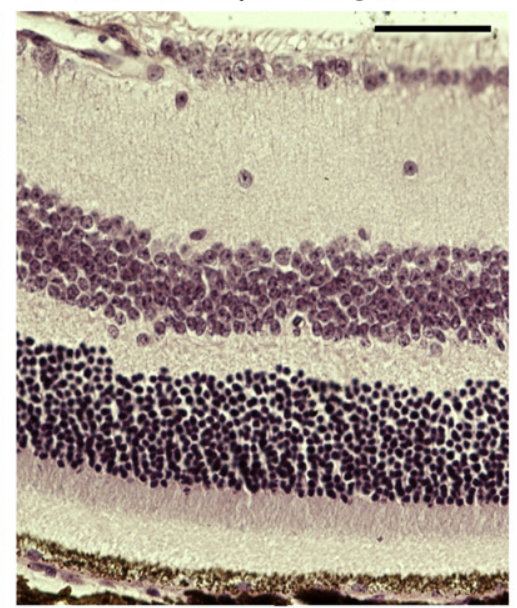

B
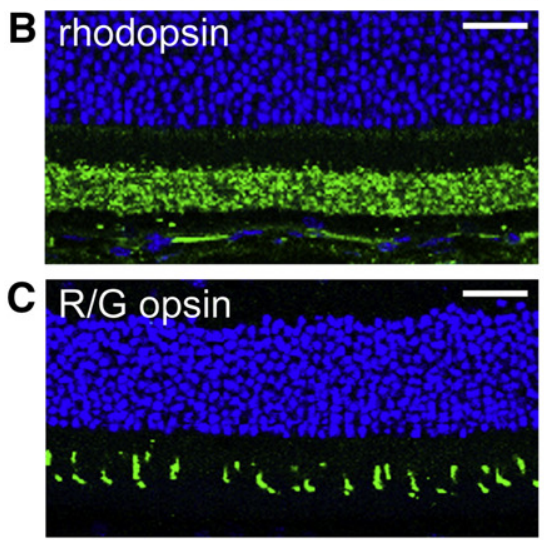
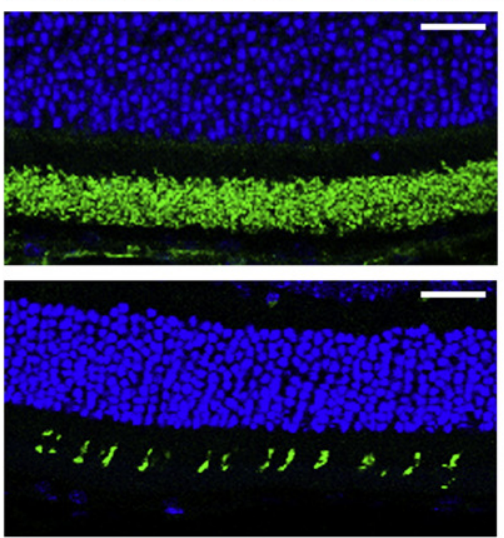

12 month-old $\beta 5^{-/-}$
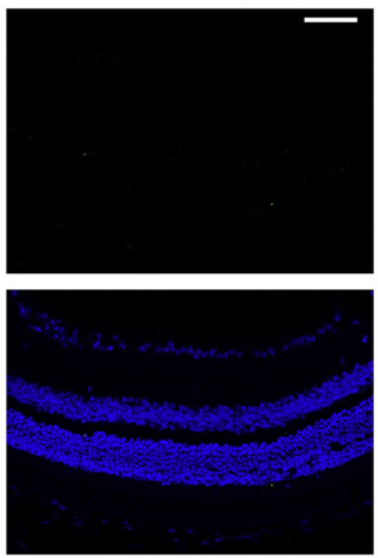

12 month-old $\beta 5^{-/}$, grape diet
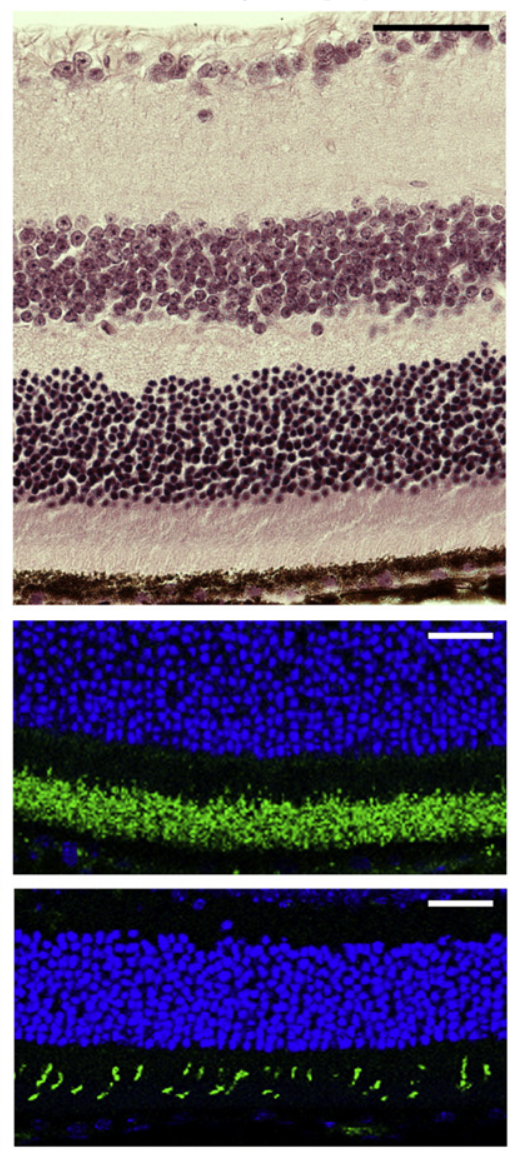

D 6 month-old $\beta 5^{-/-}$
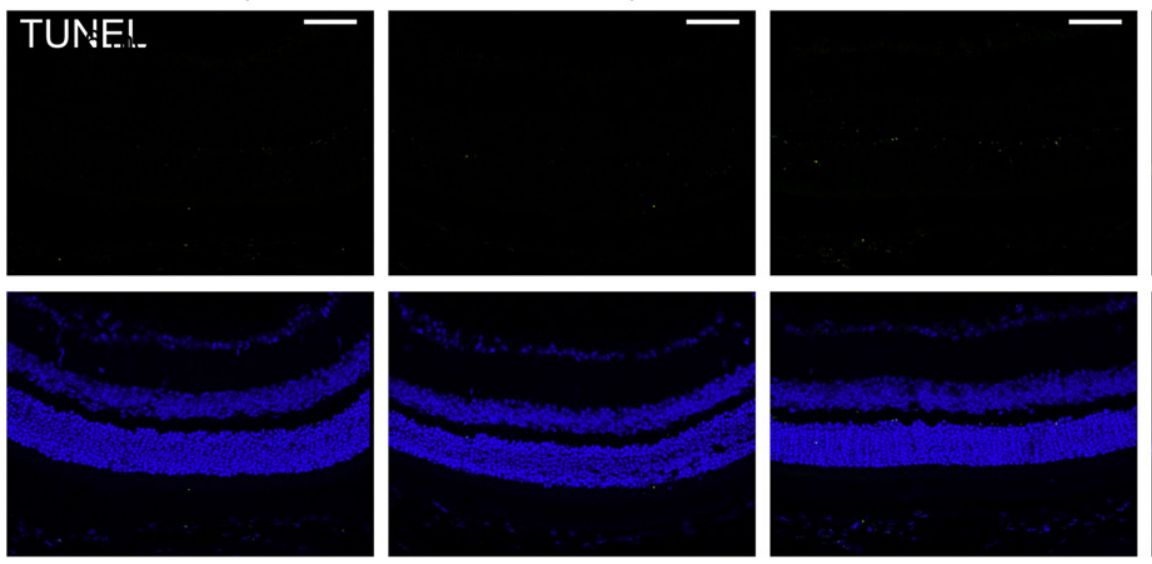

1 month-old RCS rat
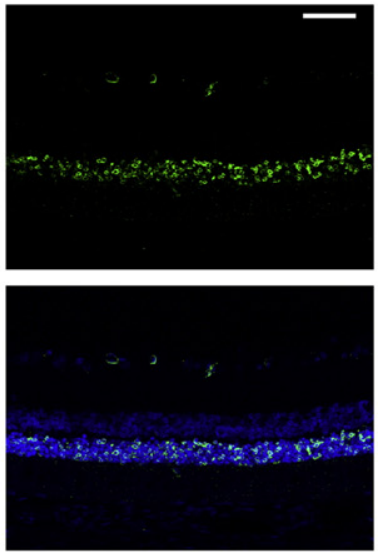

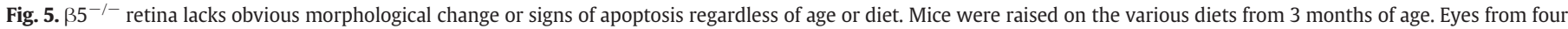

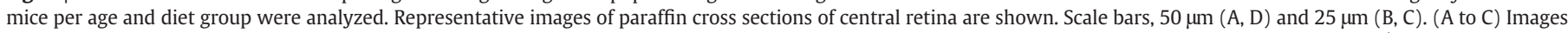

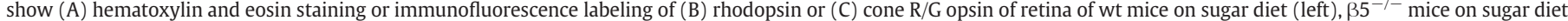

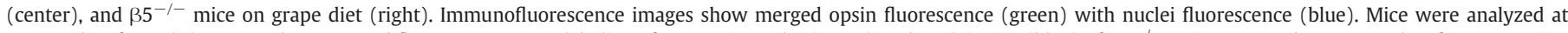

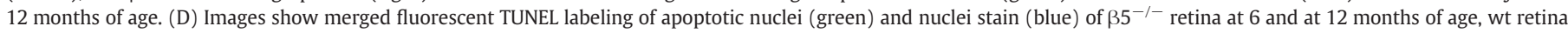

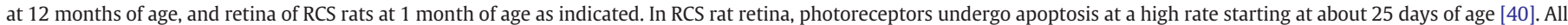

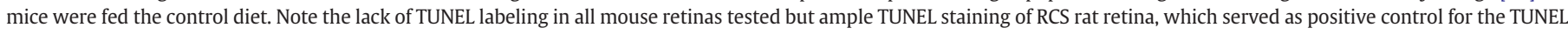
assay.

prevent HNE-adduct formation (data not shown) or the solubilization of actin by either 5 or $20 \mu \mathrm{M}$ HNE (Fig. 9A). Either HNE concentration solubilized 28 to $41 \%$ of actin regardless of antioxidant regimen, which was not significantly different $(n=3$ independent experiments, with duplicate samples in each). After a 1-h HNE pulse, actin remained soluble to a similar extent for all time points tested, up to
$24 \mathrm{~h}$ (Fig. 9B). Significant actin destabilization persisted regardless of whether RPE cells received 5 or $20 \mu \mathrm{M}$ HNE or whether any of the three antioxidants previously tested were added during a 24-h recovery period (Fig. 9C, quantification of three independent experiments not shown). All effects shown were specific to the actin cytoskeleton as tubulin remained insoluble under all conditions (Figs. 9A to C, 
A

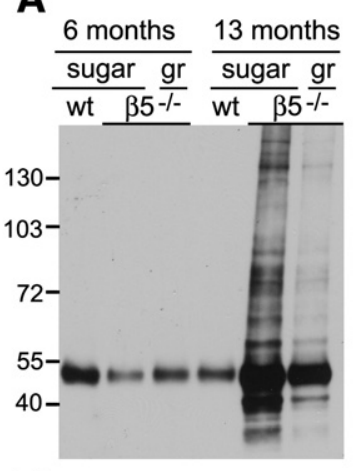

B

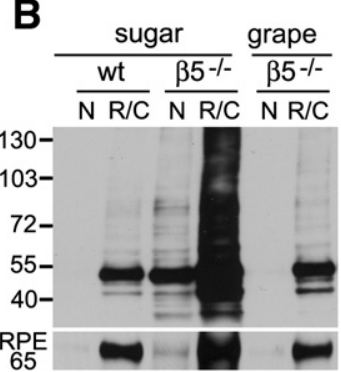

C

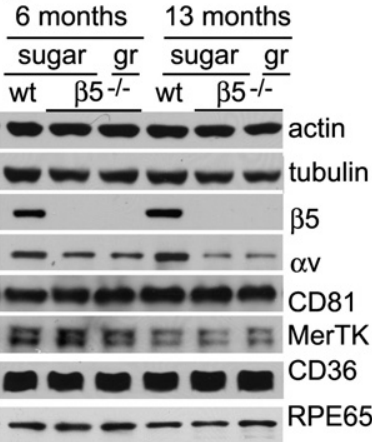

D

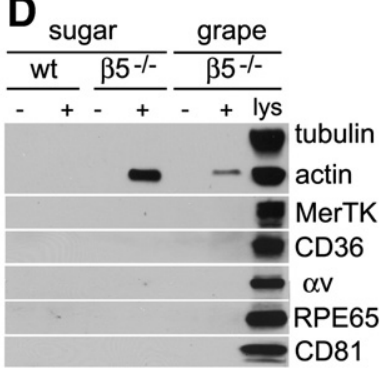

Fig. 6. Grape dietary supplementation prevents HNE modification of actin in RPE/choroid of $\mathrm{B5}^{-/-}$mice with age. (A) Immunoblotting detection of HNE adducts specifically in $35^{-/-}$ eyes of mice on sugar (sugar) but not on grape diet (gr) at 13 months of age compared to younger wt or $35^{-1-}$ eyes or age-matched wt eyes as indicated. (B) HNE immunoblot detects HNE-modified proteins mainly in the RPE/choroid $(\mathrm{R} / \mathrm{C})$ rather than in the neural retina $(\mathrm{N})$ regardless of genotype or diet. Reprobing for RPE65 confirmed enrichment of RPE tissue in $\mathrm{R} / \mathrm{C}$ fraction (bottom). (C) Immunoblotting detection of similar total amounts of proteins relevant for the cytoskeleton (actin, $\alpha$-tubulin), phagocytosis ( $\beta 5$ and $\alpha \mathrm{v}$ integrin, CD81, MerTK, and CD36), and visual cycle (RPE65), in age-matched eyes of wt and $35^{-/}$ mice on sugar control diet and of $\beta 5^{-/-}$mice on grape diet (gr). (D) Immunoprecipitation detection with HNE antibodies (lanes + ) but not with nonimmune IgG (lanes -) of HNE-modified actin but not HNE-modified tubulin or other proteins tested as indicated in eyes of $35^{-/-}$mice on control diet and, at lower levels, in eyes of $35^{-/-}$mice on grape diet. Whole-eye lysates in the right lane (lys) served as detection control. The same blot membrane is shown probed sequentially for actin, tubulin, MerTK, and CD36. Blots represent typical results as obtained from four independent experiments. For each dataset in (A) to (D), a total of 12 mice were analyzed for each age/strain/diet group.

tubulin rows). Taken together, these results suggest that providing antioxidants to RPE cells as tested did not prevent acute HNE destabilization of actin or detectably promote actin restabilization.

\section{Discussion}

Aging of the retina and RPE is associated with increased levels of oxidative damage $[24,25]$. It is generally assumed that oxidative stress also plays a role in the development or progression of AMD [26,27]. This is supported by studies demonstrating that increasing oxidative insult in experimental animal models results in visual impairment and in pathology as seen in atrophic AMD [28-31]. However, it is poorly understood precisely how physiological levels of chronic sublethal oxidative stress affect retina and/or RPE functionality. Here, we demonstrate oxidative protein modification specific to the RPE that coincides with age-related photoreceptor dysfunction in $\mathrm{B5}^{-/-}$ mice. In these mice, a primary defect in phagocytic rhythm directly due to a lack of the outer segment recognition receptor $\alpha v \beta 5$ integrin causes gradual accumulation of autofluorescent lipofuscin-like granules [9]. Although the exact mechanism triggering lipofuscin accumulation in $35^{-/-}$RPE is still under investigation, it is likely that it involves impaired phagolysosomal processing. We detect both lipofuscin buildup and increased levels of oxidized lipids and protein starting at about 6 month of age and we have not yet found experimental conditions under which one occurs without the other. Thus, we do not know at this time if these changes are independent or if
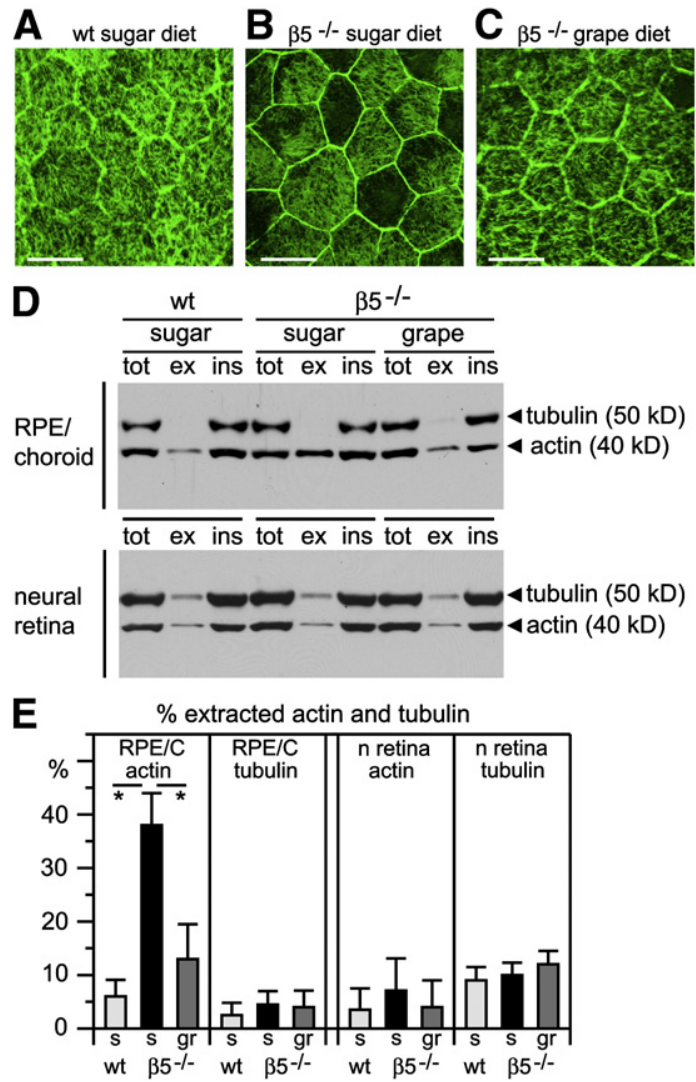

Fig. 7. Actin is less stable in the in situ RPE of 13-month-old $\beta 5^{-/-}$mice on sugar diet compared to age-matched wt mice on sugar control diet and $B 5^{-/-}$mice on grape diet. (A, B, and C) Comparison of fluorescent phalloidin detection of F-actin in RPE whole mounts of mice as indicated. Images show representative maximal projections. Scale bars, $20 \mu \mathrm{m}$. (D) Immunoblotting detection of actin and tubulin in RPE/choroid (top) or neural retina (bottom) of wt or $35^{-/-}$mice on diets as indicated. Samples were either solubilized directly with HNTG (lanes tot) or fractionated by initial incubation with CSB for $1 \mathrm{~min}$, yielding extractable proteins (lanes ex), and remaining, insoluble proteins were subsequently solubilized in HNTG (lanes ins). (E) Quantification of percentage actin and tubulin extractable by incubation for $1 \mathrm{~min}$ in mild extraction buffer. Bars show means $\pm S D, n=4$. Asterisks indicate significant differences between bars connected by line. (A-E). Experiments were performed four times independently. A total of 12 mice were analyzed for each age/strain/diet group. Of each mouse one eye each was used for microscopy and for differential extraction.

lipofuscin causes oxidative modifications or vice versa. Gradually, $\beta 5^{-/-}$photoreceptors also become dysfunctional. We did not detect elevated levels of oxidative modifications in neural retina of $\beta 5^{-/-}$ mice even in mice at a high age when ERGs showed that their photoreceptor cells largely failed to respond to light. This suggests that increased levels of oxidative damage of the RPE may result in photoreceptor dysfunction even if it does not directly harm photoreceptor themselves.

Because increasing oxidative damage in aging $35^{-/-}$RPE directly correlates with photoreceptor dysfunction, we decided to check for alterations in RPE proteins that are particularly important for photoreceptor support. We did not find abnormalities in steady-state protein levels of any of the candidate proteins we tested. We conclude that oxidative stress in the eyes of aging $35^{-1-}$ mice does not reach a level that would cause nonspecific cell damage. Moreover, none of the RPE's known phagocytic receptors nor the critical visual cycle isomerase RPE65 were modified by HNE to a detectable extent. However, we detected an age-dependent increase in HNE adducts of the microfilament constituent actin in the RPE of $35^{-/-}$mice but not in the RPE of age-matched wt mice nor in $\beta 5^{-/-}$neural retina. Furthermore, stability of the actin cytoskeleton was dramatically altered solely in the RPE of $\mathrm{B5}^{-/-}$mice of age. Thus, HNE-actin content directly correlates with microfilament destabilization in the RPE in 


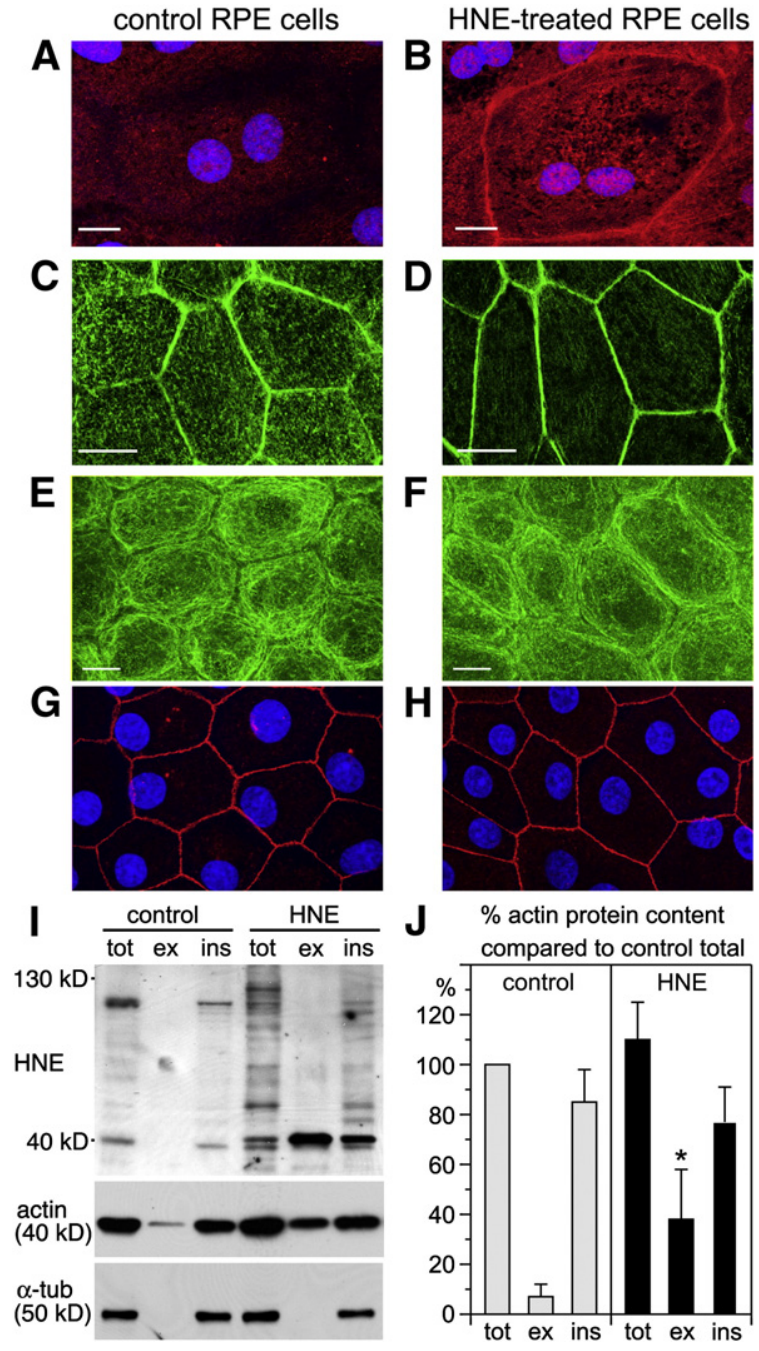

Fig. 8. Short-term HNE treatment is sufficient to specifically destabilize actin in rat RPE cells in primary culture. Microscopy images show representative fields of one of three independent experiments comparing RPE cells incubated for $1 \mathrm{~h}$ with $0.2 \%$ ethanol in DMEM as control (left column) or with $20 \mu \mathrm{M}$ HNE in DMEM (right column). Scale bars, $5 \mu \mathrm{m}(\mathrm{A}, \mathrm{B})$ and $20 \mu \mathrm{m}$ (C to $\mathrm{H})$. (A and B) Overlay of HNE immunolabeling (red) with nuclei stain (blue) in a single $x-y$ confocal scan. (C and D) Phalloidin labeling of F-actin in cells preincubated for 1 min with CSB before fixation. (E-H) Double immunolabeling for tubulin (green, E and F) and ZO-1 (red, G and $\mathrm{H}$ ) shown with nuclei counterstain (blue). (I) HNE immunoblotting of total HNTG cell lysates (tot), soluble proteins obtained by 1 min incubation with CSB (ex), and insoluble proteins (ins) obtained by solubilization of remaining proteins in HNTG. The same samples tested for HNE were also tested on another blot membrane for both actin and tubulin (blotting detection as indicated). (J) Quantification of actin protein levels in control (gray bars) and HNE-treated (black bars) samples as in (I). Bars show means $\pm \mathrm{SD}, n=3$ normalized to total actin in control cells $(100 \%)$. Three independent identical experiments were performed. Student's $t$ test was used to compare equivalent fractions between control and HNE-treated cells. Asterisk indicates significant change in actin content upon treatment with HNE.

situ. Interestingly, a recent proteomic study reported higher levels of HNE-modified actin (among numerous other proteins) in the brain of Alzheimer disease patients relative to brain of control subjects, although it was not determined if this was associated with F-actin destabilization [32]. Proteomic analysis has detected an increased HNE load of numerous proteins in human retina with age that includes HNE-actin [24]. Tanito and colleagues identified a number of specific HNE adducts in rat neural retina subjected to damaging light [33]. Most of them were functionally related to energy metabolism and neither actin nor tubulin was among them, but their study did not investigate modifications in the RPE. Like ours, these studies show that the overall increase in HNE-adduct load is due to considerable modification of select proteins rather than due to low-level modifications of proteins in general. Interestingly, we found

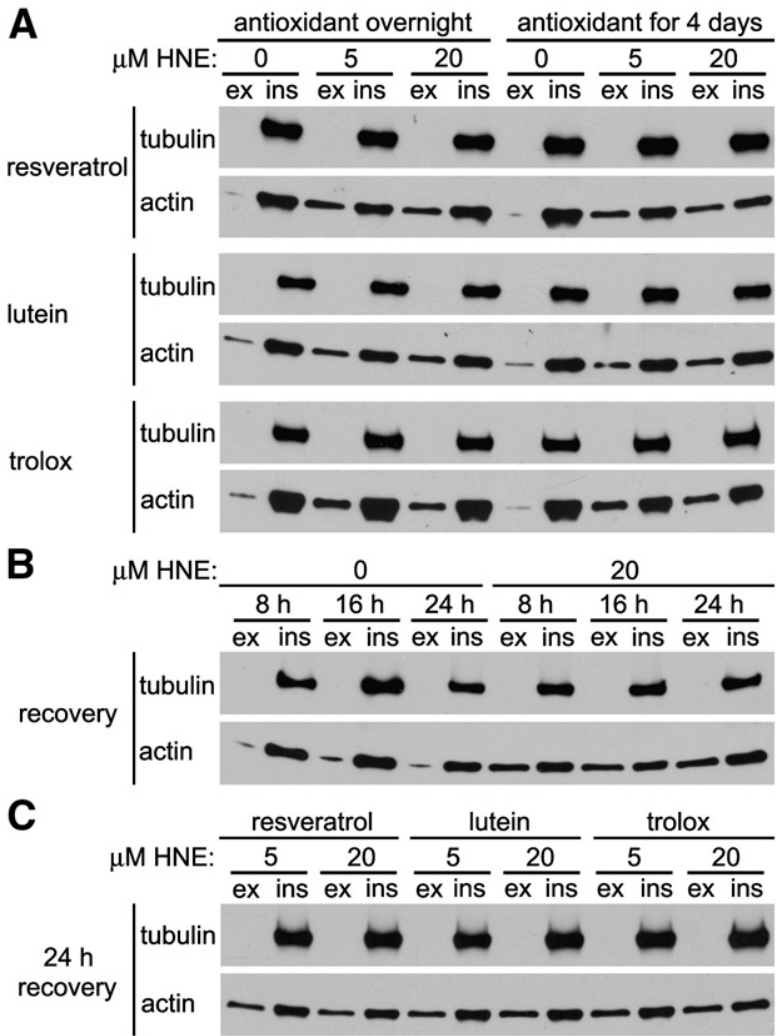

Fig. 9. Antioxidants do not prevent or reverse HNE-induced actin destabilization in rat RPE cells in primary culture. Representative immunoblots detecting tubulin and actin of rat primary RPE cells as indicated among soluble proteins (ex) obtained by $1 \mathrm{~min}$ incubation with CSB or among insoluble proteins (ins) obtained by extraction of remaining proteins with HNTG. All experiments were performed three times independently. (A) Cells were pretreated with $30 \mu \mathrm{M}$ resveratrol, $50 \mu \mathrm{M}$ lutein, or $20 \mu \mathrm{M}$ trolox overnight or for 4 days as indicated before $1 \mathrm{~h}$ incubation with solvent or 5 or $20 \mu \mathrm{M} \mathrm{HNE}$ in the continued presence of antioxidants and immediate analysis. (B) After $1 \mathrm{~h}$ incubation with solvent or $20 \mu \mathrm{M}$ HNE, cells were further incubated in growth medium without HNE for 8 to $24 \mathrm{~h}$ as indicated before analysis. (C) After $1 \mathrm{~h}$ incubation with 5 or $20 \mu \mathrm{M} \mathrm{HNE}$ as indicated, cells were further incubated for $24 \mathrm{~h}$ in growth medium without HNE but with $30 \mu \mathrm{M}$ resveratrol, $50 \mu \mathrm{M}$ lutein, or $20 \mu \mathrm{M}$ trolox as indicated before analysis.

obvious variability in autofluorescent granule load and in the extent of actin destabilization even among RPE in individual eyes and especially in eyes of mice fed an antioxidant-enriched diet. This observation leads us to speculate that RPE damage and prevention thereof occur at the single-cell level and are influenced by differences in individual cell properties that may include differences in actin-dependent structures and in abundance of melanin- and/or lipofuscin-containing granules (for a review of RPE mosaicism, please see [34]).

We complemented our studies of the RPE in vivo with cell culture experiments proving that short-term incubation with HNE is sufficient to solubilize actin in RPE cells. F-actin associated with the apical surface of the RPE and its microvilli was more obviously disrupted than circumferential microfilaments in both $35^{-/-}$RPE in situ and HNE-treated primary RPE cells. As the apical actin cytoskeleton undergoes frequent dramatic reorganization, e.g., during diurnal outer segment phagocytosis, it is possible that dynamic apical actin is more vulnerable to HNE modification than lateral actin. RPE microfilaments were vulnerable even at HNE concentrations low enough not to disassemble tight junctions or microtubules. The specific sensitivity of F-actin to HNE destabilization may be characteristic to RPE. Other studies testing HNE incubation of cells in culture (albeit at higher concentrations than ours) have shown that fibroblasts and neuronal cells mainly disassemble microtubules and endothelial cells lose focal adhesions and lateral junctions [23,35]. Changes in monolayer permeability suggesting altered cell-cell junctions have 
also been reported to occur in the ARPE-19 cell line upon HNE treatment [36]. We did not observe obvious changes in these vital cell structures in our assays investigating unpassaged primary RPE but we did not directly test epithelial barrier properties. As our HNE immunoblots show a number of HNE-proteins of molecular sizes other than actin in $35^{-/-}$RPE with age, it is clear that the selection of candidate proteins we examined was not comprehensive. However, the identification of RPE actin as specifically vulnerable to HNE modification provides important new insight into the functional alterations in RPE cells affected by physiological levels of oxidative stress. Like aging $35^{-1-}$ RPE, human RPE/retina accumulate lipofuscin and HNE adducts over a lifetime [24]. Our results predict that human RPE with age may acquire actin cytoskeletal abnormalities that could impair their support for photoreceptor cells. The same probably holds true for other experimental animal models of retinal dysfunction that involve oxidative damage [28-31,33].

Based on the presence of oxidative modifications in human RPE, it has long been hypothesized that antioxidant supplements and/or altering dietary habits to increase natural antioxidant consumption may be beneficial to prevent or delay progression of AMD (summarized in [37]). Here, we tested if increasing dietary antioxidant content by enriching an otherwise unchanged diet with grapes or with marigold extract providing lutein/zeaxanthin reduced oxidative damage and preserved vision in our animal model. The results were dramatic. Increasing dietary intake of either grapes or lutein/zeaxanthin was sufficient to prevent RPE oxidation, cytoskeletal damage, and vision loss. This suggests that photoreceptor loss of function in this model occurs as a consequence of oxidative damage to the RPE. The beneficial effects of the grape diet for both rod and cone photoreceptor function, even if consumed only during young adulthood (from 3 to 6 months of age) or during midlife (from 6 to 9 months of age), suggests that age-related vision loss is a result of cumulative, lifelong oxidative insult. ERG recordings from 1-year-old wt mice did not detect differences in light responses between wt mice that had consumed control or grape diet from 4 months of age (Supplementary Fig. S5). This lack of benefit for normal retinal function suggests that dietary antioxidants prevent the vision loss specifically caused by pathological oxidative stress rather than enhancing visual function independently. Unlike the RPE in our wt mice kept under standard vivarium conditions, human RPE accumulates oxidative damage with age and individuals with high oxidative burden, such as smokers, are at increased risk for AMD. We speculate therefore that long-term increase in dietary antioxidant intake will probably reduce RPE oxidative damage in the human eye and may delay onset of age-related visual impairment.

We do not know at this time whether the antioxidants exert their effects locally by acting directly on the RPE or whether they induce systemic changes that secondarily reduce oxidative burden on the RPE. Little is known about the availability of phenolic compounds as included in grapes to specific tissues after dietary intake. Intake of a lutein-rich diet has been shown to increase lutein levels in the macula of human patients [38]. This suggests that dietary lutein reaches the retina/RPE. However, as the mouse eye differs from the human eye in that its retina does not possess a macular region, mechanisms accumulating dietary lutein available to the human macula may not exist in the murine eye. Considering that antioxidants did not alter degree or duration of actin destabilization by added HNE at least within the time period we tested in our cell culture experiments, we propose that dietary antioxidants reduce availability of HNE to the RPE in our mice rather than its efficacy.

In our experimental design we chose to assess efficacy of dietary antioxidants from natural sources. Mice consumed antioxidants as part of a healthy diet rather than receiving periodic supplements. Our lutein diet provided about $1.65 \mathrm{mg}$ lutein per mouse per day, which had shown health benefits to mice earlier [39]. Taking into account their body weight and food intake, mice on our grape diet consumed about 3.5 servings of grapes per day. This is not excessive given that 5 servings of fruit and vegetables are recommended to be a part of a healthy diet. We did not determine the minimum amount of grapes that would still be protective in our animal model. Furthermore, we did not test if a diet combining lutein/zeaxanthin and grape additives may be more effective in preventing oxidative damage and vision loss, which is an intriguing possibility especially because the antioxidants prevalent in the two dietary additives are chemically different.

Mice differ from humans not just in body size but in many aspects of physiology as well as in lifestyle and compliance. Yet, we conclude from our study that a lifelong diet enriched in natural antioxidants is directly beneficial for RPE and retinal health and function.

Supplementary materials related to this article can be found online at doi:10.1016/j.freeradbiomed.2011.11.021.

\section{Acknowledgments}

We thank Ms. Kathryn Silva for excellent technical support. We thank Dr. Zoraida Freitas from Kemin Health for generously supplying the FloraGlo lutein/zeaxanthin mix. This work was supported by National Institutes of Health Grant EY013295 from the National Eye Institute (to S.C.F.) and a Research Award by The California Table Grape Commission (to S.C.F.). E.F.N. was supported by the Institut National de la Santé et de la Recherche Médicale, the Université Pierre et Marie Curie-Paris 6, the Centre National de la Recherche Scientifique, and the Départment de Paris (to Institut de la Vision) and by Young Investigator Grants from the Fondation Voir et Entendre and Fondation Bettencourt Schueller.

\section{References}

[1] Feeney-Burns, L.; Hilderbrand, E. S.; Eldridge, S. Aging human RPE: morphometric analysis of macular, equatorial, and peripheral cells. Invest. Ophthalmol. Vis. Sci. 25:195-200; 1984.

[2] Rozanowska, M.; Pawlak, A.; Rozanowski, B.; Skumatz, C.; Zareba, M.; Boulton, M. E.; Burke, J. M.; Sarna, T.; Simon, J. D. Age-related changes in the photoreactivity of retinal lipofuscin granules: role of chloroform-insoluble components. Invest. Ophthalmol. Vis. Sci. 45:1052-1060; 2004.

[3] Haralampus-Grynaviski, N. M.; Lamb, L. E.; Clancy, C. M.; Skumatz, C.; Burke, J. M.; Sarna, T.; Simon, J. D. Spectroscopic and morphological studies of human retinal lipofuscin granules. Proc. Natl. Acad. Sci. U. S. A. 100:3179-3184; 2003.

[4] Sparrow, J. R.; Boulton, M. RPE lipofuscin and its role in retinal pathobiology. Exp. Eye Res. 80:595-606; 2005.

[5] Wu, Y.; Yanase, E.; Feng, X.; Siegel, M. M.; Sparrow, J. R. Structural characterization of bisretinoid A2E photocleavage products and implications for age-related macular degeneration. Proc. Natl. Acad. Sci. U. S. A. 107:7275-7280; 2010.

[6] Zhou, J.; Jang, Y. P.; Kim, S. R.; Sparrow, J. R. Complement activation by photooxidation products of A2E, a lipofuscin constituent of the retinal pigment epithelium. Proc. Natl. Acad. Sci. U. S. A. 103:16182-16187; 2006.

[7] Klein, R.; Chou, C. F.; Klein, B. E.; Zhang, X.; Meuer, S. M.; Saaddine, J. B. Prevalence of age-related macular degeneration in the US population. Arch. Ophthalmol. 129: 75-80; 2011

[8] Augood, C. A.; Vingerling, J. R.; de Jong, P. T.; Chakravarthy, U.; Seland, J.; Soubrane, G.; Tomazzoli, L.; Topouzis, F.; Bentham, G.; Rahu, M.; Vioque, J.; Young, I. S.; Fletcher, A. E. Prevalence of age-related maculopathy in older Europeans: the European Eye Study (EUREYE). Arch. Ophthalmol. 124:529-535; 2006.

[9] Nandrot, E. F.; Kim, Y.; Brodie, S. E.; Huang, X.; Sheppard, D.; Finnemann, S. C. Loss of synchronized retinal phagocytosis and age-related blindness in mice lacking

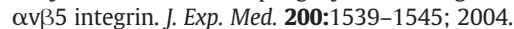

[10] Huang, X.; Griffiths, M.; Wu, J.; Farese Jr., R. V.; Sheppard, D. Normal development, wound healing, and adenovirus susceptibility in $\beta 5$-deficient mice. Mol. Cell. Biol. 20:755-759; 2000.

[11] Nandrot, E. F.; Anand, M.; Sircar, M.; Finnemann, S. C. Novel role for $\alpha v \beta 5$ integrin in retinal adhesion and its diurnal peak. Am. J. Physiol. Cell Physiol. 290: C1256-C1262; 2006.

[12] Lee, E. H.; Faulhaber, D.; Hanson, K. M.; Ding, W.: Peters, S.; Kodali, S.; Granstein, R. D. Dietary lutein reduces ultraviolet radiation-induced inflammation and immunosuppression. J. Invest. Dermatol. 122:510-517; 2004.

[13] Sasaki, M.; Yuki, K.; Kurihara, T.; Miyake, S.; Noda, K.; Kobayashi, S.; Ishida, S.; Tsubota, K.; Ozawa, Y. Biological role of lutein in the light-induced retinal degeneration. J. Nutr. Biochem. in press, doi:10.1016/j.jnutbio.2011.01.006.

[14] Finnemann, S. C. Focal adhesion kinase signaling promotes phagocytosis of integrin-bound photoreceptors. EMBO J. 22:4143-4154; 2003.

[15] Mansoor, S.; Gupta, N.; Patil, A. J.; Estrago-Franco, M. F.; Ramirez, C.; Migon, R.; Sapkal, A.; Kuppermann, B. D.; Kenney, M. C. Inhibition of apoptosis in human retinal pigment epithelial cells treated with benzo(e)pyrene, a toxic component of cigarette smoke. Invest. Ophthalmol. Vis. Sci. 51:2601-2607; 2010. 
[16] Sheu, S. J.; Liu, N. C.; Chen, J. L. Resveratrol protects human retinal pigment epithelial cells from acrolein-induced damage. J. Ocul. Pharmacol. Ther. 26: 231-236; 2010.

[17] Vives-Bauza, C.; Anand, M.; Shirazi, A. K.; Magrane, J.; Gao, J.; Vollmer-Snarr, H. R.; Manfredi, G.; Finnemann, S. C. The age lipid A2E and mitochondrial dysfunction synergistically impair phagocytosis by retinal pigment epithelial cells. J. Biol. Chem. 283:24770-24780; 2008.

[18] Adamus, G.; Zam, Z. S.; Arendt, A.; Palczewski, K.; McDowell, J. H.; Hargrave, P. A Anti-rhodopsin monoclonal antibodies of defined specificity: characterization and application. Vision Res. 31:17-31; 1991.

[19] Bligh, E. G.; Dyer, W. J. A rapid method of total lipid extraction and purification. Can. J. Biochem. Physiol. 37:911-917; 1959.

[20] Finnemann, S. C.; Leung, L. W.; Rodriguez-Boulan, E. The lipofuscin component A2E selectively inhibits phagolysosomal degradation of photoreceptor phospholipid by the retinal pigment epithelium. Proc. Natl. Acad. Sci. U. S. A. 99:3842-3847; 2002.

[21] Hanausek, M.; Spears, E.; Walaszek, Z.; Kowalczyk, M. C.; Kowalczyk, P.; Wendel, C.; Slaga, T. J. Inhibition of murine skin carcinogenesis by freeze-dried grape powder and other grape-derived major antioxidants. Nutr. Cancer 63:28-38; 2011.

[22] Morre, D. M.; Morre, D. J. Anticancer activity of grape and grape skin extracts alone and combined with green tea infusions. Cancer Lett. 238:202-209; 2006.

[23] Kokubo, J.; Nagatani, N.; Hiroki, K.; Kuroiwa, K.; Watanabe, N.; Arai, T. Mechanism of destruction of microtubule structures by 4-hydroxy-2-nonenal. Cell Struct. Funct. 33:51-59; 2008.

[24] Ethen, C. M.; Reilly, C.; Feng, X.; Olsen, T. W.; Ferrington, D. A. Age-related macular degeneration and retinal protein modification by 4-hydroxy-2-nonenal. Invest. Ophthalmol. Vis. Sci. 48:3469-3479; 2007.

[25] Crabb, J. W.; Miyagi, M.; Gu, X.; Shadrach, K.; West, K. A.; Sakaguchi, H.; Kamei, M.; Hasan, A.; Yan, L.; Rayborn, M. E.; Salomon, R. G.; Hollyfield, J. G. Drusen proteome analysis: an approach to the etiology of age-related macular degeneration. Proc. Natl. Acad. Sci. U. S. A. 99:14682-14687; 2002.

[26] Ding, X.; Patel, M.; Chan, C. C. Molecular pathology of age-related macular degeneration. Prog. Retin. Eye Res. 28:1-18; 2009.

[27] Hollyfield, J. G. Age-related macular degeneration: the molecular link between oxidative damage, tissue-specific inflammation and outer retinal disease: the Proctor lecture. Invest. Ophthalmol. Vis. Sci. 51:1275-1281; 2010.

[28] Imamura, Y.; Noda, S.; Hashizume, K.; Shinoda, K.; Yamaguchi, M.; Uchiyama, S. Shimizu, T.; Mizushima, Y.; Shirasawa, T.; Tsubota, K. Drusen, choroidal neovascularization, and retinal pigment epithelium dysfunction in SOD1-deficient mice: a model of age-related macular degeneration. Proc. Natl. Acad. Sci. U. S. A 103:11282-11287; 2006

[29] Dong, A.; Shen, J.; Krause, M.; Akiyama, H.; Hackett, S. F.; Lai, H.; Campochiaro, P. A. Superoxide dismutase 1 protects retinal cells from oxidative damage. $J$ Cell. Physiol. 208:516-526; 2006.

[30] Justilien, V.; Pang, J. J.; Renganathan, K.; Zhan, X.; Crabb, J. W.; Kim, S. R.; Sparrow, J. R.; Hauswirth, W. W.; Lewin, A. S. SOD2 knockdown mouse model of early AMD. Invest. Ophthalmol. Vis. Sci. 48:4407-4420; 2007.

[31] Hollyfield, J. G.; Bonilha, V. L.; Rayborn, M. E.; Yang, X.; Shadrach, K. G.; Lu, L.; Ufret, R. L.; Salomon, R. G.; Perez, V. L. Oxidative damage-induced inflammation initiates age-related macular degeneration. Nat. Med. 14:194-198; 2008.

[32] Reed, T.; Perluigi, M.; Sultana, R.; Pierce, W. M.; Klein, J. B.; Turner, D. M.; Coccia R.; Markesbery, W. R.; Butterfield, D. A. Redox proteomic identification of 4-hydroxy-2-nonenal-modified brain proteins in amnestic mild cognitive impairment: insight into the role of lipid peroxidation in the progression and pathogenesis of Alzheimer's disease. Neurobiol. Dis. 30:107-120; 2008.

[33] Tanito, M.; Haniu, H.; Elliott, M. H.; Singh, A. K.; Matsumoto, H.; Anderson, R. E. Identification of 4-hydroxynonenal-modified retinal proteins induced by photooxidative stress prior to retinal degeneration. Free Radic. Biol. Med. 41:1847-1859; 2006.

[34] Burke, J. M.; Hjelmeland, L. M. Mosaicism of the retinal pigment epithelium: seeing the small picture. Mol. Interv. 5:241-249; 2005.

[35] Usatyuk, P. V.; Parinandi, N. L.; Natarajan, V. Redox regulation of 4-hydroxy-2nonenal-mediated endothelial barrier dysfunction by focal adhesion, adherens, and tight junction proteins. J. Biol. Chem. 281:35554-35566; 2006.

[36] Qin, S.; Rodrigues, G. A. Differential roles of AMPK $\alpha 1$ and AMPK $\alpha 2$ in regulating 4-HNE-induced RPE cell death and permeability. Exp. Eye Res. 91:818-824; 2010.

[37] Seddon, J. M. Multivitamin-multimineral supplements and eye disease: age-related macular degeneration and cataract. Am. J. Clin. Nutr. 85: 304S-307S; 2007.

[38] Bone, R. A.; Landrum, J. T.; Guerra, L. H.; Ruiz, C. A. Lutein and zeaxanthin dietary supplements raise macular pigment density and serum concentrations of these carotenoids in humans. J. Nutr. 133:992-998; 2003.

[39] Koh, H. H.; Murray, I. J.; Nolan, D.; Carden, D.; Feather, J.; Beatty, S. Plasma and macular responses to lutein supplement in subjects with and without agerelated maculopathy: a pilot study. Exp. Eye Res. 79:21-27; 2004.

[40] Tso, M. O.: Zhang C. Abler, A. S.; Chang C. J: Wong F. Chang G. Q: Lam, T. T. Apoptosis leads to photoreceptor degeneration in inherited retinal dystrophy of RCS rats. Invest. Ophthalmol. Vis. Sci. 35:2693-2699; 1994. 